\title{
Aplicação do Problema Combinado - Corte de Estoque e Dimensionamento de Lotes - em uma Fábrica de Móveis
}

\author{
Giovanna Peral Salvadeo \\ Glaucia Maria Bressan ${ }^{2}$ \\ Departamento Acadêmico de Matemática, UTFPR, Cornélio Procópio, PR.
}

\begin{abstract}
Resumo. Devido aos aspectos econômicos e avanços computacionais, estudos de modelos de otimização se fazem necessários para o controle e planejamento de sistemas produtivos. Diante deste cenário, o objetivo deste trabalho é minimizar os custos de produção de uma fábrica de móveis por meio da aplicação do Problema Combinado, o qual acopla os problemas de dimensionamento de lotes e de corte de estoque. As soluções são obtidas a partir da aplicação do Método Simplex com apoio computacional e indica a quantidade a ser produzida em cada período de planejamento.

Palavras-chave. Programação Linear, Problema Combinado, Planejamento da Produção
\end{abstract}

\section{Formulação do Problema e Resultados Numéricos}

O objetivo deste trabalho é aplicar o Problema Combinado [3] para a minimização dos custos de produção de uma fábrica de móveis do município de Cornélio Procópio, PR. O Problema Combinado acopla dois problemas de otimização linear: o dimensionamento de lotes e o corte de estoque [2]. Tal problema consiste em decidir a quantidade de produtos finais a serem produzidos em cada período de planejamento tal que minimize os custos da produção, preparação e estocagem e a quantidade de placas a serem cortadas para compor produtos finais. A solução encontrada, chamada de solução ótima, é obtida pela aplicação do Método Simplex [1]. O Problema Combinado é formulado considerando-se os parâmetros disponíveis em [2] e os dados numéricos fornecidos pela fábrica de móveis desse estudo.

Parâmetros: $c_{i t}$ : custo de produção do produto $i$ no período $t$; $h p_{p t}$ : custo de estocagem da peça $p$ no período $t ; h_{i t}$ : custo de estocagem do produto $i$ no período $t ; d_{i t}$ : demanda do produto $i$ no período $t ; v_{j}$ : tempo de corte de placa no padrão $j ; a_{p j}$ : número de peças tipo $p$ no padrão $j$; $u_{t}$ : tempo máximo de operação da serra; $c p$ : custo da placa a ser cortada; $r_{p i}$. número de peças tipo $p$ necessárias para formar um produto $i$.

Variáveis de decisão (valores obtidos na solução ótima): $x_{i t}$ : quantidade do produto final $i$ produzido no período $t ; e p_{p t}$ : quantidade da peça tipo $p$ em estoque no fim do período $t ; e_{i t}$ : quantidade do produto final $i$ em estoque no fim do período $t ; y_{j t}$ : quantidade de placas

1 giovannaperal@hotmail.com - bolsista CNPq de iniciação científica

2 glauciabressan@utfpr.edu.br 
cortadas usando o padrão $j$ no período $t$. O modelo é dado pelas equações (1).

$$
\begin{aligned}
& \min \sum_{i=1}^{2} \sum_{t=1}^{2}\left(c_{i t} \cdot x_{i t}+h_{i t} . e_{i t}\right)+\sum_{j=1}^{5} \sum_{i=1}^{2} c p \cdot y_{j t}+\sum_{p=1}^{3} \sum_{t=1}^{2} h p_{p t} . e p_{p t} \\
& \text { s.a: } \quad x_{i t}+e_{i, t-1}-e_{i t}=d_{i t} \quad \forall t=1,2, \forall i=1,2 \quad \text { balanço de estoque de produtos finais } \\
& \sum_{j=1}^{5} a_{p j} \cdot y_{j t}+e p_{p, t-1}-e p_{p t}=\sum_{i=1}^{2} r_{p i} . x_{i t} \quad \text { balanço de estoque de peças } \\
& \sum_{j=1}^{5} v_{j} \cdot y_{j t} \leq u_{t} \quad \forall t=1,2, \forall j=1, \ldots 5 \text { capacidade da serra } \\
& x_{i t}, f_{i t}, y_{j t}, e_{p t} \geq 0 \quad \forall t=1,2 \quad \text { condições de não negatividade }
\end{aligned}
$$

A variável $x_{1 t}$ representa "mesa", com custo de produção $c_{l t}=255$ e demanda $d_{l t}=2$ para $t=1,2$. A variável $x_{2 t}$ representa "cadeira", com custo de produção $c_{2 t}=80$ e demanda $d_{2 t}=3$ para $t=1,2$. Os demais parâmetros fornecidos pela fábrica são $c p=120, u_{t}=300$ horas, $r_{11}=1, r_{21}=5, r_{32}=2, r_{22}=6, h_{1 t}=3, h_{2 t}=1, h p_{1 t}=0,2, h p_{2 t}=0,3, h p_{3 t}=0,5$; peças a serem cortadas são tampo $(p=1)$, pés $(p=2)$, assento/encosto $(p=3)$; os valores de $a_{p j}$ estão na Tabela 1.

Tabela 1: Padrões de Corte de Peças para Produção de Itens Finais

\begin{tabular}{|c|c|c|c|c|}
\hline Padrão de Corte & Peça tipo 1 $(p=1)$ & Peça tipo 2 $(p=2)$ & Peça tipo 3 $(p=3)$ & Tempo de corte \\
\hline$j=1$ & 2 & 0 & 0 & $v_{l}=1$ \\
\hline$j=2$ & 1 & 88 & 0 & $v_{2}=1,2$ \\
\hline$j=3$ & 0 & 0 & 35 & $v_{3}=1,5$ \\
\hline$j=4$ & 0 & 0 & 45 & $v_{4}=1,4$ \\
\hline$j=5$ & 1 & 8 & 15 & $v_{5}=1,5$ \\
\hline
\end{tabular}

Soluções ótimas foram obtidas a partir da execução do modelo com apoio computacional do software LINDO ("Linear Interactive and Discrete Optimizer"). Para $t=2$ períodos, a solução ótima indica que o custo mínimo de produção é $\mathrm{R} \$ 1508,09$, produzindose $x_{11}=4$ mesas e $x_{21}=6$ cadeiras em $t=1$. Comparando-se com o custo de produção que atende a demanda por período (produção de 2 mesas e 3 cadeiras por período) esta solução proporciona economia de $1,54 \%$. Para $t=5$, a solução ótima apresenta o custo mínimo de $\mathrm{R} \$ 3758,09$, produzindo-se $x_{21}=15$ cadeiras em $t=1$, gerando estoque, e $x_{14}=10$ mesas em $t=4$. Esta solução proporciona economia de $1,852 \%$ em relação à solução adotada pela fábrica, supondo demanda e preços constantes. Com os resultados obtidos, pode-se concluir que a aplicação do Problema Combinado em conjunto com o Método Simplex no estudo da fábrica de móveis é eficiente, pois fornece custo mínimo, sugerindo a antecipação da produção de alguns itens, e proporciona economia em relação à produção por período.

\section{Referências}

[1] M. Arenales et al., Pesquisa Operacional: para cursos de engenharia, Rio de Janeiro, Elsevier, (2007).

[2] G. M. Bressan, Solução de sistemas lineares esparsos - aplicação à programação de lotes e cortes, Dissertação de Mestrado em Matemática Aplicada, USP, (2003).

[3] M. C. N. Gramani, Otimização do processo de cortagem acoplado ao planejamento da produção, Tese de Doutorado em Engenharia Elétrica, Unicamp, (2001). 